Review

\title{
Fluorescent proteins as tools to aid protein production
} Wei Wen Su*

\author{
Address: Department of Molecular Biosciences and Bioengineering, University of Hawaii at Manoa, Hawaii 96822, USA \\ Email: Wei Wen Su* - wsu@hawaii.edu \\ * Corresponding author
}

Published: 25 April 2005

Microbial Cell Factories 2005, 4:12 doi:10.1 186/1475-2859-4-12
Received: 04 March 2005

Accepted: 25 April 2005

This article is available from: http://www.microbialcellfactories.com/content/4/I/12

(C) 2005 Su; licensee BioMed Central Ltd.

This is an Open Access article distributed under the terms of the Creative Commons Attribution License (http://creativecommons.org/licenses/by/2.0), which permits unrestricted use, distribution, and reproduction in any medium, provided the original work is properly cited.

\begin{abstract}
Fluorescent proteins are genetically encoded, highly versatile reporters useful for monitoring various aspects of recombinant protein production. In addition to the widely popular green fluorescent protein (GFP) from Aequorea victoria, a variety of other fluorescent proteins have been discovered that display a wide range of spectral properties. Synthetic variants have also been developed to overcome limitations associated with their wild-type counterparts. Having a large repertoire of fluorescent proteins with diverse traits opens new opportunities for rapid monitoring and optimization of recombinant protein production.
\end{abstract}

\section{Review \\ Introduction}

Expression of recombinant proteins from a variety of host organisms is now a common practice. However, production of properly folded proteins with high yield and purity may not always be achieved. Issues such as folding, solubility, protein stability, transcription and translation efficiency, posttranslational processing, secretion, metabolic burden and other stress responses resulting from recombinant protein production, as well as protein purification, need to be addressed in order to obtain biologically active recombinant proteins with high purity and yield [1]. In this regard, genetically encoded fluorescent reporters provide ample new opportunities to better tackle these issues. Since the demonstration of the Aequorea victoria green fluorescent protein (GFP) as a versatile reporter [2], several additional GFP-like fluorescent proteins with various colors have been discovered and their genes cloned [3]. Synthetic fluorescent protein variants have also been developed, exhibiting traits distinct from their wild-type counterparts. The properties of selected fluorescent protein variants derived from the A. victoria GFP and the Discosoma red fluorescent protein (DsRed) [4] are summarized in Table 1. Fluorescence spectra of enhanced GFP variants along with DsRed are shown in Figure 1[5], and fluorescence of purified protein variants derived from DsRed [6] are shown in Figure 2. Readers are referred to the work of Labas et al. [7] for information of additional fluorescent proteins. These GFP-like proteins each has its own unique properties, while sharing common structural, biochemical and photophysical characteristics [3]. GFPlike proteins are relatively small $(25-30 \mathrm{kDa})$ and their fluorescence mechanism is self-contained, requiring no cofactors. These unique properties make GFP-like proteins very attractive tools in non-invasive biological monitoring applications. As a tool to improve recombinant protein production, fluorescent proteins can be used to monitor the protein product or the cellular processes relevant to recombinant protein production.

\section{Monitoring protein production, secretion, and culture growth}

Fluorescent proteins are commonly used as a reporter for a protein of interest, normally by tagging the fluorescent protein reporter to the protein of interest via genetic fusion. Functional fusion of Aequorea GFP to a broad 
Table I: Properties of selected fluorescent proteins

\begin{tabular}{|c|c|c|c|c|c|}
\hline $\begin{array}{l}\text { Fluorescent } \\
\text { Protein }\end{array}$ & $\begin{array}{l}\text { Excitation Peak } \\
(\mathrm{nm})\end{array}$ & $\begin{array}{l}\text { Emission Peak } \\
(\mathrm{nm})\end{array}$ & $\begin{array}{l}\text { Extinction } \\
\text { Coefficient }\left(\mathrm{M}^{-1} \mathrm{~cm}^{-}\right. \\
\text {l) }\end{array}$ & $\begin{array}{l}\text { Fluorescence } \\
\text { Quantum Yield }\end{array}$ & Reference \\
\hline EBFP & 383 & 445 & 31,000 & 0.25 & {$[5]$} \\
\hline ECFP & 434 & 477 & 26,000 & 0.40 & {$[5]$} \\
\hline Cerulean CFP & 433 & 475 & 43,000 & 0.62 & [38] \\
\hline EGFP & 489 & 508 & 55,000 & 0.60 & [5] \\
\hline EYFP & 514 & 527 & 84,000 & 0.61 & [5] \\
\hline Venus YFP & 515 & 528 & 92,200 & 0.57 & [39] \\
\hline Citrine YFP & 516 & 529 & 77,000 & 0.76 & {$[40]$} \\
\hline DsRed & 558 & 583 & 75,000 & 0.79 & [6] \\
\hline mRFPI & 584 & 607 & 50,000 & 0.25 & {$[6]$} \\
\hline mHoneydew & $487 / 504$ & $537 / 562$ & 17,000 & 0.12 & {$[6]$} \\
\hline mBanana & 540 & 553 & 6,000 & 0.70 & [6] \\
\hline mOrange & 548 & 562 & 71,000 & 0.69 & {$[6]$} \\
\hline mTangerine & 568 & 585 & 38,000 & 0.30 & {$[6]$} \\
\hline mStrawberry & 574 & 596 & 90,000 & 0.29 & {$[6]$} \\
\hline mCherry & 587 & 610 & 72,000 & 0.22 & [6] \\
\hline
\end{tabular}

range of protein partners at either $\mathrm{N}$ - or $\mathrm{C}$ - terminus has been reported, and a direct quantitative correlation between the GFP fluorescence intensity and the titer or even the functional activity of the fusion partner can often be established $[8,9]$. To minimize potential interference by the GFP tag on its fusion partner, it is desirable and sometimes necessary to incorporate a peptide linker to allow sufficient spatial separation of the two protein moieties to assure fusion protein stability and functionality. Flexible linkers lacking large bulky hydrophobic residues (e.g. GSAGSAAGSGEF [10]) are commonly used, while hydrophilic helix-forming linker peptides have been reported to be superior to flexible linkers in some cases [11]. To allow removal of the GFP tag, an enzymatic cleavage site (e.g. enterokinase or Factor Xa cleavage sites) can be engineered into the linker. It is preferred to splice the GFP/linker to the N-terminus of the target protein, provided such fusion does not impair the target protein function and stability. With the majority of the enzymes commonly used for tag removal, this fusion orientation enables elimination of the tag without leaving extraneous amino acid residues on the target protein after cleavage. Alternatively, chemical cleavage based on cyanogen bromide, formic acid, or hydroxylamine may be considered, provided the target proteins are not susceptible to cutting by these chemical agents. Further information of tag removal can be found in a comprehensive review by Hearn and Acosta [12]. In addition to tandem fusion, insertional fusion (i.e. by inserting the protein of interest into GFP or vise versa) may also be feasible [13]. Recombinant protein production can be monitored non-invasively, in situ, and almost in real time, by monitoring culture fluorescence using on-line optical sensors [14,15].
This information is useful in determining the optimal product harvest time to avoid product degradation [16] and to devise process control strategies to optimize culture/operating conditions to improve recombinant protein production $[8,17]$. GFP has also been used to monitor recombinant virus titers in cell cultures [18], and cell density in microbial [15], animal [19], and plant cell cultures [8]; the cell growth information can be used, in turn, to optimize the culture process for improved recombinant protein production (e.g. by optimizing the feeding profiles of the limiting nutrient or the promoter inducer, or by determining the optimal product harvest time $[8,17])$. Additionally, GFP-fusion coupled with flow cytometric analysis is useful for profiling recombinant protein expression among different cell subpopulations, and selection of high-producing cells [9].

GFP-fusion can also be used for monitoring protein secretion and other subcellular protein localization and trafficking events. In the event direct GFP fusion hampers protein secretion, alternative protein fusion strategies may be sought. One plausible approach is to express GFP and a protein of interest as a cleavable chimeric polyprotein. By targeting the polyprotein to the secretory pathway, the target protein and the GFP tag may become separated and secreted as individual proteins. Feasibility of such approach has been demonstrated in fungi and plant cells for the successful in-vivo cleavage of an glucoamylaseinterleukin-6 fusion protein [20] and a fusion antimicrobial polyprotein [21], respectively. Cellular processing in plant cells of a polyprotein that consists of DsRed-GFP fusion linked by a Kex2 cleavage sequence [22] is currently being investigated in the author's laboratory. In another 

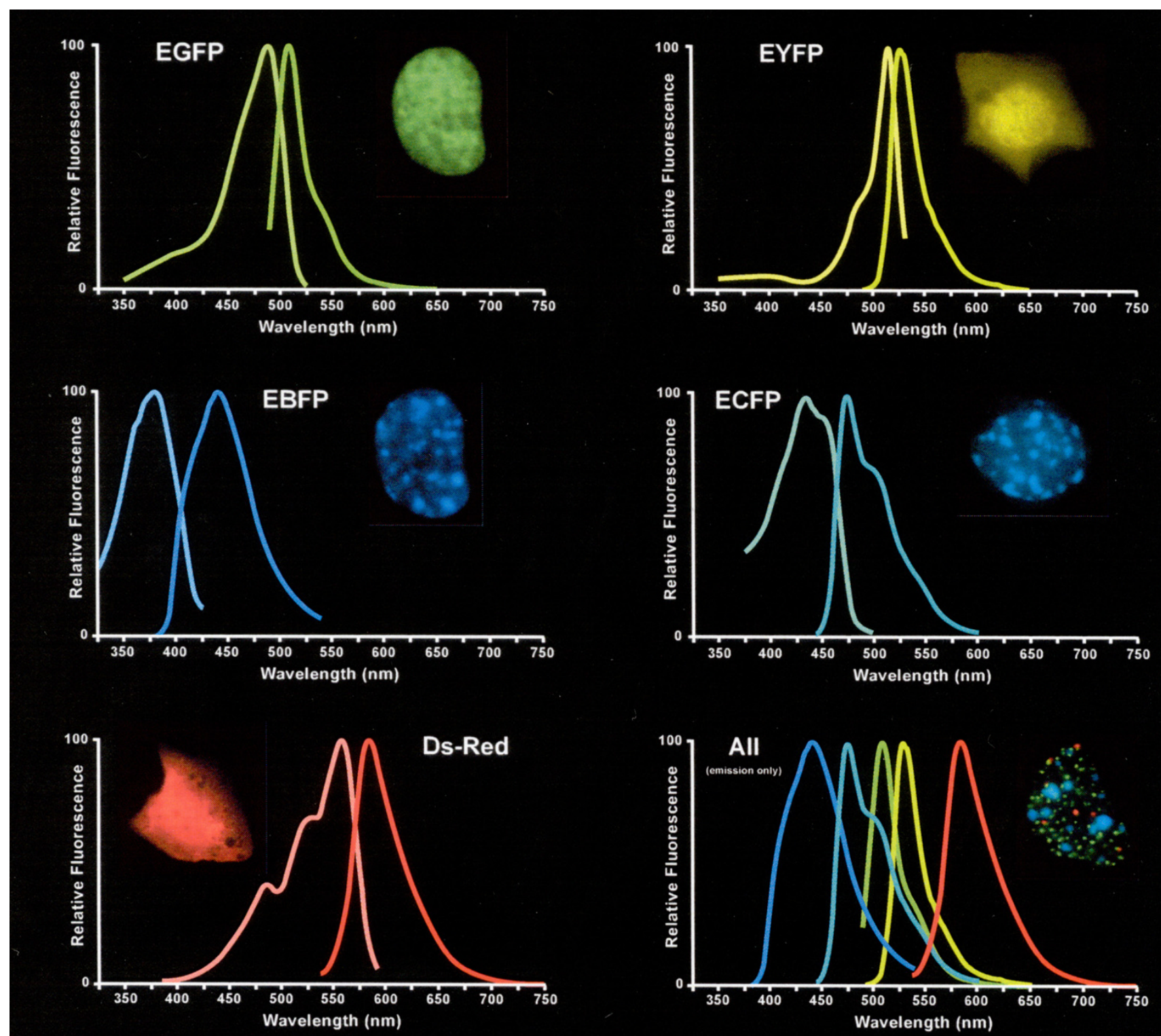

Figure I

Fluorescence spectra of EGFP variants and DsRed (reproduced with the permission of [5]).

possible approach, one may express the target gene and GFP in a dicistronic vector by incorporating an internal ribosome entry site (IRES) [23]. One additional possibility would be to express target protein and GFP as separate genes, but from the identical promoter. If a constant ratio between GFP fluorescence and target protein concentration could be established, the independent GFP could be used for fluorescent monitoring. Fluorescent protein reporters can also be used to probe protein-protein interactions that regulate the protein secretion process [24], potentially leading to development of molecular strategies that improve recombinant protein secretion.

\section{Monitoring protein purification}

The fact that GFP fluorescence is readily detectable makes it a very attractive tool for optimizing purification of recombinant proteins. Poppenborg et al. [25] optimized immobilized metal affinity separation of a histidine-rich protein tagged with GFP by tracking the fluorescence of the fusion protein. Since GFP is a highly hydrophobic 


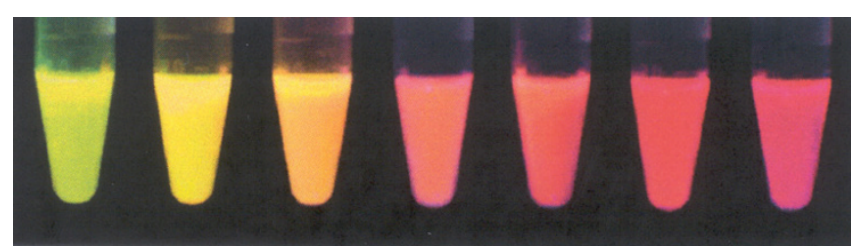

Figure 2

Fluorescence of DsRed variants developed by Shaner et al [6] (from left to right, mHoneydew, mBanana, mOrange, tdTomato, mTangerine, mStrawberry, mCherry; reproduced with the permission of [6]; refer to the same reference for details).

protein, recovery of GFP-fusion proteins can be facilitated by using hydrophobic interaction chromatography (HIC) [26]. GFP has also been engineered to allow affinity purification. Paramban et al [27] developed a chimeric GFP tag having an internal hexa-histidine sequence. Such a GFP tag allows efficient purification of GFP-fusion proteins based on immobilized metal affinity separation, as well as maximum flexibility for protein or peptide fusions since both termini of the GFP are available.

\section{Monitoring protein folding}

Correct folding is one of the key challenges in recombinant protein production using simple hosts like Escherichia coli. GFP has been proposed as a folding reporter. By fusing GFP to a panel of proteins, Waldo et al [10] demonstrated that display of GFP fluorescence in the E. coli colonies expressing the fusion proteins indicated proper folding of GFP's fusion partner. De Marco [28] however cautioned that observation of GFP fluorescence from the fusion protein may not guarantee the fusion partner have reached its native structure.

Recently, Waldo and coworkers [29] reported a novel split-GFP system that consists of a small (GFP $\beta$ strand 11; GFP 11) and a complementary large fragment (GFP $\beta$ strand 1-10; GFP 1-10). Neither fragment by itself displays fluorescence, but GFP fluorescence emerges upon self-association of the two complementary fragments. These researchers demonstrated that by tagging target proteins with the GFP-11 tag, the solubility of the target proteins can be checked by mixing with the GFP 1-10 fragment in vitro or by co-expressing the GFP 1-10 fragment in vivo. Appearance of GFP fluorescence suggests the target protein is soluble. This split-GFP may also be useful for detecting protein-protein interaction in vivo, similar to the luciferase fragment complementation systems $[30,31]$.

\section{Monitoring cellular responses}

In addition to direct monitoring of protein expression, processing, and secretion, fluorescent proteins can also be used to monitor cellular events that are directly or indirectly related to recombinant protein production. For instance, FRET (fluorescence resonance energy transfer)based GFP sensors have been developed to detect proteolysis in vivo. FRET-based GFP sensors have also been developed for measuring intracellular concentration of nitric oxide, calcium, cAMP, zinc, activation of G protein-coupled receptor (GPCR), and PKA-mediated phosphorylation [9]. Redox sensitive GFP variants have been developed for monitoring the cellular oxidative states, which strongly affect protein folding. In addition, intracellular pH can be measured using GFP. Metabolic stresses induced by recombinant protein over-expression may also be monitored in vivo using GFP linked to stressinduced promoters as a reporter.

\section{Optical sensing of culture GFP fluorescence}

The presence of cell aggregates, debris, and other light absorbing/scattering compounds in the culture medium contributes to the "inner filter effect" (IFE) that could distort the optical measurement of culture GFP fluorescence. Real-time compensation of IFE in monitoring cultures expressing GFP-fusion proteins typically involves establishing a mathematical model to link the IFE to cell density, and to use an on-line laser turbidity sensor to report the biomass density needed in the calculation of the IFE [32]. An obvious drawback of such an approach is the requirement of a turbidity sensor in addition to the optical sensor for monitoring culture fluorescence. We recently developed a technique that allows real-time compensation of IFE during on-line monitoring of culture GFP fluorescence, without the need for an additional biomass sensor [33]. This was achieved by developing a model-based state observer, using the extended Kalman filter (EKF) and on-line measurement of GFP culture fluorescence using an optical light-rod sensor.

\section{Applications involving multiple fluorescent protein variants}

Given the many facets of its applications, multiple fluorescent protein reporters could potentially be used in parallel for multi-color in vivo sensing. For instance, GFP may be used to tag the recombinant protein product, while a red fluorescent protein could be linked to a stress-responsive promoter such as the heat-shock promoter groEL to monitor stress induced by recombinant protein overexpression in E. coli [34]. Having a large repertoire of fluorescent proteins with diverse spectral properties is also necessary for multiplex FRET-based sensing applications. Through both structure-based modification and evolutionary methods for protein engineering, several robust variants of the Aequorea GFP have been created with blue, 
cyan, and yellow colors [35]. In a recent paper by Shaner et al [6], development of a panel of novel monomeric red, orange and yellow fluorescent proteins derived from the Discosoma DsRed was reported. These new variants also show additional traits that are useful for monitoring recombinant protein production.

\section{Monomeric fluorescent protein variants}

Wild type DsRed is an obligate tetramer. When fused to a protein of interest, the fusion protein often forms aggregates, hampering normal localization, trafficking and protein-protein interactions of the protein of interest. A monomeric DsRed variant, called mRFP1, was developed by disrupting each subunit interface via insertion of arginines, and then using directed evolution to accelerate chromophore maturation and to restore fluorescence, which takes 33 substitutions [36]. mRFP1 was further improved by subjecting to additional rounds of directed evolution [6]. The resulting eight variants display corresponding emission peaks ranging from 537 to $610 \mathrm{~nm}$. Some of these new variants also show better tolerance to $\mathrm{N}$ - and C- terminal fusions, higher extinction coefficients, quantum yields, and photostability, though no single variant has acquired all the desirable traits [6]. Since GFP is known to have high tolerance to either $\mathrm{N}$ - or C-terminal fusions, and DsRed and GFP share similar structures, Shaner et al [6] engineered GFP-type termini into mRFP1, rendering improved tolerance to protein fusion in the new variant. Among the new monomeric variants, mCherry (excitation at $587 \mathrm{~nm}$, emission at $610 \mathrm{~nm}$ ) is the most red-shifted, and has the best photostability, fastest maturation (15 min) and excellent $\mathrm{pH}$ resistance and tolerance to N-terminal fusions. The mOrange variant (excitation at $548 \mathrm{~nm}$, emission at $562 \mathrm{~nm}$ ) has high extinction coefficient and quantum yield, and is shown to be a superior FRET acceptor for GFP variants.

\section{Conclusion}

The repertoire of fluorescent protein variants has continued to expand, and is now covering almost the entire color spectrum. With the advances in directed evolution techniques [37], each of these new proteins is likely to be further improved. The availability of improved multicolor fluorescent protein reporters will undoubtedly lead to development of innovative techniques that enable more effective multiplex cellular sensing, and allow more efficient on-line optimization of recombinant protein production.

\section{Acknowledgements}

The author is grateful to the funding supports from the United States National Science Foundation (BES97-12916 and BESOI-26191) and the United States Department of Agriculture (0I-34I35-I I 295 and 58-3 I48-9080).

\section{References}

I. Schmidt FR: Recombinant expression systems in the pharmaceutical industry. Appl Microbiol Biotechnol 2004, 65:363-372.

2. Chalfie M, Tu Y, Euskirchen G, Ward WW, Prasher DC: Green fluorescent protein as a marker for gene expression. Science 1994, 263:802-805.

3. Verkhusha VV, Lukyanov KA: The molecular properties and applications of Anthozoa fluorescent proteins and chromoproteins. Nat Biotechnol 2004, 22:289-296.

4. Matz MV, Fradkov AF, Labas YA, Savitsky AP, Zaraisky AG, Markelov $M L$, Lukyanov SA: Fluorescent proteins from nonbioluminescent Anthozoa species. Nat Biotechnol 1999, 17:969-973.

5. Patterson G, Day RN, Piston D: Fluorescent protein spectra. J Cell Sci 200I, I I 4:837-838.

6. Shaner NC, Campbell RE, Steinbach PA, Giepmans BN, Palmer AE, Tsien RY: Improved monomeric red, orange and yellow fluorescent proteins derived from Discosoma sp. red fluorescent protein. Nat Biotechnol 2004, 22: I 567-I572.

7. Labas YA, Gurskaya NG, Yanushevich YG, Fradkov AF, Lukyanov KA, Lukyanov SA, Matz MV: Diversity and evolution of the green fluorescent protein family. Proc Natl Acad Sci U S A 2002, 99:4256-426I.

8. Liu S, Bugos RC, Dharmasiri N, Su WW: Green fluorescent protein as a secretory reporter and a tool for process optimization in transgenic plant cell cultures. J Biotechnol 200I, 87:I-16.

9. March JC, Rao G, Bentley WE: Biotechnological applications of green fluorescent protein. Appl Microbiol Biotechnol 2003, 62:303-315.

10. Waldo GS, Standish BM, Berendzen J, Terwilliger TC: Rapid protein-folding assay using green fluorescent protein. Nat Biotechnol 1999, I 7:691-695.

II. Arai R, Ueda H, Kitayama A, Kamiya N, Nagamune T: Design of the linkers which effectively separate domains of a bifunctional fusion protein. Protein Eng 200 I, 14:529-532.

12. Hearn MT, Acosta D: Applications of novel affinity cassette methods: use of peptide fusion handles for the purification of recombinant proteins. J Mol Recognit 200I, I 4:323-369.

13. Baird GS, Zacharias DA, Tsien RY: Circular permutation and receptor insertion within green fluorescent proteins. Proc Natl Acad Sci U S A 1999, 96: I I 24 I-I I 246.

14. Su WW, Guan PZ, Bugos RC: High-level secretion of functional green fluorescent protein from transgenic tobacco cell cultures: characterization and sensing. Biotechnol Bioeng 2004, 85:610-619.

15. Randers-Eichhorn L, Albano CR, Sipior J, Bentley WE, Rao G: Online green fluorescent protein sensor with LED excitation. Biotechnol Bioeng 1997, 55:921-926.

16. Cha HJ, Dalal NG, Pham MQ, Vakharia VN, Rao G, Bentley WE: Insect larval expression process is optimized by generating fusions with green fluorescent protein. Biotechnol Bioeng 1999, 65:316-324.

17. Chae HJ, Delisa MP, Cha HJ, Weigand WA, Rao G, Bentley WE: Framework for online optimization of recombinant protein expression in high-cell-density Escherichia coli cultures using GFP-fusion monitoring. Biotechnol Bioeng 2000, 69:275-285.

18. Cote J, Bourget L, Garnier A, Kamen A: Study of adenovirus production in serum-free 2935 s suspension culture by GFP. expression monitoring. Biotechnol Prog 1997, I 3:709-7I4.

19. Hunt L, Jordan M, De Jesus M, Wurm FM: GFP-expressing mammalian cells for fast, sensitive, noninvasive cell growth assessment in a kinetic mode. Biotechnol Bioeng 1999, 65:201-205.

20. Contreras R, Carrez D, Kinghorn JR, van den Hondel CA, Fiers W: Efficient KEX2-like processing of a glucoamylase-interleukin-6 fusion protein by Aspergillus nidulans and secretion of mature interleukin-6. Biotechnology (N Y) 1991, 9:378-38I.

21. Francois IE, De Bolle MF, Dwyer G, Goderis IJ, Woutors PF, Verhaert PD, Proost P, Schaaper WM, Cammue BP, Broekaert WF: Transgenic expression in Arabidopsis of a polyprotein construct leading to production of two different antimicrobial proteins. Plant Physiol 2002, I 28: I 346-I358.

22. Jiang L, Rogers JC: Functional analysis of a Golgi-localized Kex2p-like protease in tobacco suspension culture cells. Plant J 1999, 1 8:23-32.

23. Urwin P, Yi L, Martin H, Atkinson H, Gilmartin PM: Functional characterization of the EMCV IRES in plants. Plant J 2000, 24:583-589. 
24. Pimpl P, Denecke J: Protein-protein interactions in the secretory pathway, a growing demand for experimental approaches in vivo. Plant Mol Biol 2002, 50:887-902.

25. Poppenborg L, Friehs K, Flaschel E: The green fluorescent protein is a versatile reporter for bioprocess monitoring. J Biotechnol 1997, 58:79-88.

26. Penna TC, Ishii M, Junior AP, de Oliveira Nascimento L, de Souza LC, Cholewa $O$ : Evaluation of recombinant green fluorescent protein, under various culture conditions and purification with HiTrap hydrophobic interaction chromatography resins. Appl Biochem Biotechnol 2004, I I 3- I I 6:453-468.

27. Paramban RI, Bugos RC, Su WW: Engineering green fluorescent protein as a dual functional tag. Biotechnol Bioeng 2004, 86:687-697.

28. de Marco A: A step ahead: combining protein purification and correct folding selection. Microb Cell Fact 2004, 3: 12.

29. Cabantous S, Terwilliger TC, Waldo GS: Protein tagging and detection with engineered self-assembling fragments of green fluorescent protein. Nat Biotechnol 2005, 23:102-107.

30. Paulmurugan R, Gambhir SS: Monitoring protein-protein interactions using split synthetic renilla luciferase protein-fragment-assisted complementation. Anal Chem 2003, 75: I584- I589.

31. Paulmurugan R, Gambhir SS: Firefly luciferase enzyme fragment complementation for imaging in cells and living animals. Anal Chem 2005, 77:I295-I302.

32. Konstantinov KB, Dhurjati P, Van Dyk T, Majarian W, LaRossa R: Real-time compensation of the inner filter effect in high-density bioluminescent cultures. Biotechnol Bioeng 1993, 42: I 190-I 198.

33. Su WW, Liu B, Lu WB, Xu NS, Du GC, Tan JL: Observer-based online compensation of inner filter effect in monitoring fluorescence of GFP-expressing plant cell cultures. Biotechnol Bioeng 2005:accepted for publication.

34. Gill RT, Valdes JJ, Bentley WE: A comparative study of global stress gene regulation in response to overexpression of recombinant proteins in Escherichia coli. Metab Eng 2000, 2:178-189.

35. Patterson $\mathrm{GH}$ : A new harvest of fluorescent proteins. Nat Biotechnol 2004, 22: 1524-1525.

36. Campbell RE, Tour O, Palmer AE, Steinbach PA, Baird GS, Zacharias DA, Tsien RY: A monomeric red fluorescent protein. Proc Natl Acad Sci U S A 2002, 99:7877-7882.

37. Lutz S, Patrick WM: Novel methods for directed evolution of enzymes: quality, not quantity. Curr Opin Biotechnol 2004, | 5:29|-297.

38. Rizzo MA, Springer GH, Granada B, Piston DW: An improved cyan fluorescent protein variant useful for FRET. Nat Biotechnol 2004, 22:445-449.

39. Nagai T, Ibata K, Park ES, Kubota M, Mikoshiba K, Miyawaki A: A variant of yellow fluorescent protein with fast and efficient maturation for cell-biological applications. Nat Biotechnol 2002, 20:87-90.

40. Griesbeck O, Baird GS, Campbell RE, Zacharias DA, Tsien RY: Reducing the environmental sensitivity of yellow fluorescent protein. Mechanism and applications. J Biol Chem 200I, 276:29188-29194

\section{Publish with Biomed Central and every} scientist can read your work free of charge

"BioMed Central will be the most significant development for disseminating the results of biomedical research in our lifetime. "

Sir Paul Nurse, Cancer Research UK

Your research papers will be:

- available free of charge to the entire biomedical community

- peer reviewed and published immediately upon acceptance

- cited in PubMed and archived on PubMed Central

- yours - you keep the copyright
BiolMedcentral 